\title{
Numerical investigation on the effect of channelled and unchannelled screens on smoke contamination in atriums upper balconies with open upstand
}

\author{
Mohammed Mutafi ${ }^{1}$, Mohammad Nasif $^{1 *}$, William Pao ${ }^{1}$ and Feras Ismail ${ }^{2}$ \\ ${ }^{1}$ Universiti Teknologi PETRONAS, 32610 Seri Iskandar, Perak Darul Ridzuan, Malaysia. \\ ${ }^{2}$ Power Generation Research Centre, Collage of Engineering University Tenaga Nasional, Selangor, \\ Malaysia.
}

\begin{abstract}
Channel screens are used to restrict the smoke from spreading laterally under the first balcony. Effect of channel screens on smoke contamination in atrium upper balconies with the presence of balcony open upstand and $1 \mathrm{~m}$ deep down stand at the fire compartment is investigated in this paper. Fire dynamic simulator (FDS6) which is a computational fluid dynamic (CFD) software was utilized to conduct the simulation. A comparison between the results of smoke contamination with the presence and omission of channeling screens showed that the height of smoke contamination in atrium upper balconies increased by $90 \%$ in case of no channel screens at the fire compartment are installed. A new correlation obtained from this work is able to predict the height of smoke contamination in atrium upper balconies with the presence of $1 \mathrm{~m}$ deep down stand, balcony open upstand and no channel screens.
\end{abstract}

\section{Introduction}

Smoke toxic gases are found to be the main cause of death in a fire incident. Smoke in general has three different hazards which are visibility, thermal hazards and toxicity. In United States, it was reported that most fire victims died because of the inhalation of toxic gases of the smoke [1].

The word atrium is used to describe a building with a large space at the center and contains multiple floor. This modern design of building has been widely used in airports, hotels, hospitals and shopping malls. The open space of the atrium allow the smoke to spread easily during a fire incident inside an atrium which may endanger the life of occupants. When fire takes place in an atrium compartment, It was expected that the bulk amount of smoke leaving the fire compartment rises vertically towards the atrium ceiling. However, it was found by previous research that sometimes smoke directed inward the atrium upper balconies rather than completely rising upward. Consequently, smoke contamination occurs at that particular level. This phenomenal causes risk to the occupant's life.

Cox [2] studied the reason that make the smoke curl into the balcony of the atrium. $\mathrm{He}$ found that the raising plume entrains more air as it moves upward toward the ceiling and because of the less supply of air from the side of the plume that is facing the atrium, a low pressure region is created inside the balcony causing the smoke to curl into the balcony which cause a smoke contamination at that specific balcony. Previous researches [3-4] found that

*Corresponding author: mohammad.nasif@utp.edu.my 
it's essential to study the effect of building structure on smoke contamination occurrence. Hence, the effects of balcony breadth, width of fire compartment opening and the depth of down stand were studied. Moreover, the effect of the channelling screen which is installed beneath the first balcony and used to restrict the lateral spread of the smoke was investigated only with the presence of balcony solid upstand. Therefore, the effect of channel screen in case of using balcony open upstand is investigated in this paper.

In this study, the results of the smoke contamination occurrence in case of using channel screen is compared to the results when no channelling screens are used.

\section{Model development}

The geometry used in this study is a full scale three levels atrium modeled using fire dynamic simulator (FDS) which is a computational fluid dynamic (CFD) software that models fluid flow driven by fire. It solves numerically a form of the Naiver-Stokes equations of a low speed fluid flow, thermally - driven flow with an emphasis on smoke and heat transport from fires [7].

A numerical investigation of the effects of different building structure parameters is performed in this work using (FDS). The balcony breadths used in this research are $5 \mathrm{~m}, 3 \mathrm{~m}$, $2 \mathrm{~m}$ and $1.5 \mathrm{~m}$ whereas the values of fire compartment opening width are $10 \mathrm{~m}, 8 \mathrm{~m}, 6 \mathrm{~m}, 4 \mathrm{~m}$ and $2 \mathrm{~m}$. As for the heat release rate, the values of 1.6 MW, 3.2 MW and 4.7 MW were selected for this study to be consistent with the recommended design fire range in an atrium [3] and corresponded to those used by [9]. A $1 \mathrm{~m}$ down stand and an open balcony upstand have been used for all cases. The dimensions of the atrium used in this research are like the atrium dimensions used in Tan experiment but for full scale [3] Upstand structure modelled as shown in figure 1(c).

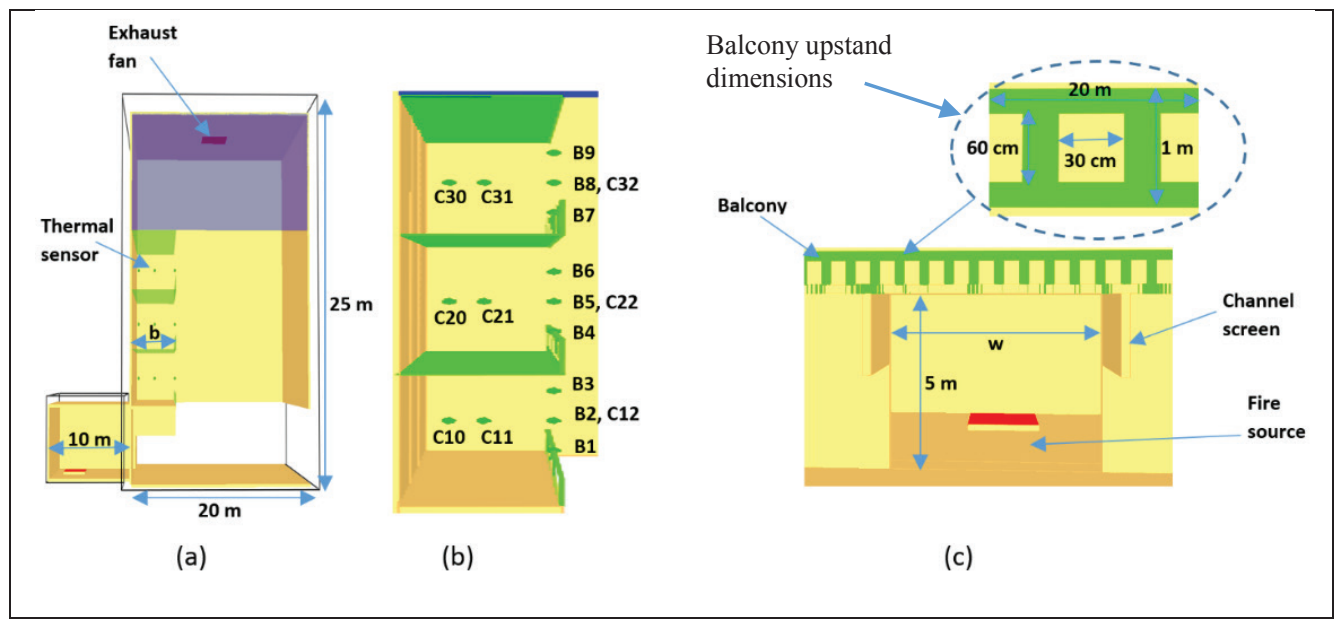

Fig. 1. Schematic drawing of atrium and fire compartment (a) side view of atrium, (b) Location of temperature sensor, (c) Front view of fire compartment with the balcony upstand

$\frac{D_{\text {spill }}^{*}}{\Delta x}$ ratio is used in (FDS) in order to determine the grid size in modelling [5]. The criterion that was utilized in this study for choosing an appropriate mesh size was set by Harrison [7]. The criterion for the size of grid cells is shown in equation (1) and (2). 


$$
\begin{aligned}
& \mathrm{n}_{\text {spill }}^{*}=\frac{\mathrm{D}_{\text {spill }}^{*}}{\Delta \mathrm{x}} \geq 0.9 \\
& D_{\text {spill }}^{*}=\left(\frac{Q_{c} / w}{\rho C_{p} T \sqrt{g}}\right)^{\frac{2}{3}}
\end{aligned}
$$

Where $D_{\text {spill }}^{*}$ is characteristic length of plume for determining the grid size $(\mathrm{m}), \mathrm{n}_{\text {spill }}^{*}$ is coefficient for determining the grid size, $\Delta \mathrm{X}$ is grid dimension in $\mathrm{X}$-axis, $\mathrm{Qc}$ is convective heat flow layer below spill edge, $\rho$ is air density at ambient condition, $\mathrm{Cp}$ is a specific heat, $\mathrm{T}$ is absolute temperature and $\mathrm{g}$ is gravity acceleration. Hence, a grid size of $200 \mathrm{~mm}$ met the criteria mentioned above and it was selected for all simulations. The total number of mesh elements in the atrium space and fire compartment is 2332800 and 81000 respectively. Values adopted to the simulation like the balcony breadth (b), fire compartment opening width (w) and heat release rate (HRR) were varied for each case. However, down stand depth was kept constant as $1 \mathrm{~m}$ for all cases. The maximum heat release rate used in this study is 4.8MW which is considered acceptable according to past studies performed for shopping mall fires with sprinklers fire protection system. The parameters used in the simulation are listed in Table 1.

Table 1. Values adopted to simulation

\begin{tabular}{|c|c|c|c|}
\hline Case & $\begin{array}{c}\text { Balcony Breadth b } \\
(\mathbf{m})\end{array}$ & $\begin{array}{c}\text { Fire compartment opening } \\
\text { width w (m) }\end{array}$ & $\begin{array}{c}\text { Heat Release Rate } \\
(\mathbf{k W})\end{array}$ \\
\hline $\mathbf{1}$ & 5 & 6 & 1581 \\
\hline $\mathbf{2}$ & 3 & 4 & 4740 \\
\hline $\mathbf{3}$ & 2 & 4 & 3160 \\
\hline $\mathbf{4}$ & 2 & 2 & 1581 \\
\hline $\mathbf{5}$ & 1.5 & 4 & 1581 \\
\hline $\mathbf{6}$ & 1.5 & 2 & 4740 \\
\hline $\mathbf{7}$ & 3 & 6 & 3160 \\
\hline
\end{tabular}

\section{Results and discussion}

In this comparison study, 7 cases were selected and each case was simulated twice with a channel screen and without channel screen. The comparison is based on the smoke temperature, smoke contamination occurrence and correlation.

\subsection{Comparison of smoke temperature}

Tan [3] recognized that smoke contamination occurrence can be indicated by the smoke temperature at that balcony. Tan found out that when the smoke temperature inside the balcony is $\geq 10^{\circ} \mathrm{C}$ above the ambient temperature which was assumed to be $20^{\circ} \mathrm{C}$, the smoke contamination occurs in that balcony. [8] and [9] used this criterion to determine the smoke contamination inside the atrium's balconies. To measure the temperature in the balcony, 15 thermocouples were installed in (FDS6) at the edge and along the breadth of the balcony. The sensors position is similar to Tan's experiment. Figure 2 (a) illustrates the smoke temperature at the edge of the balcony for both cases with channel screen and without channel screen. (b) and (c) shows the temperature along the balcony breadth in case of using channel screen and not using it, respectively. 


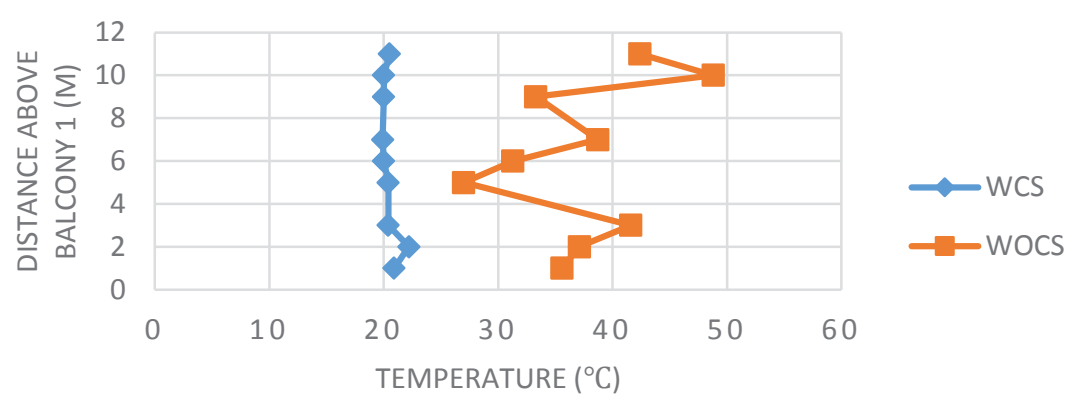

(a)

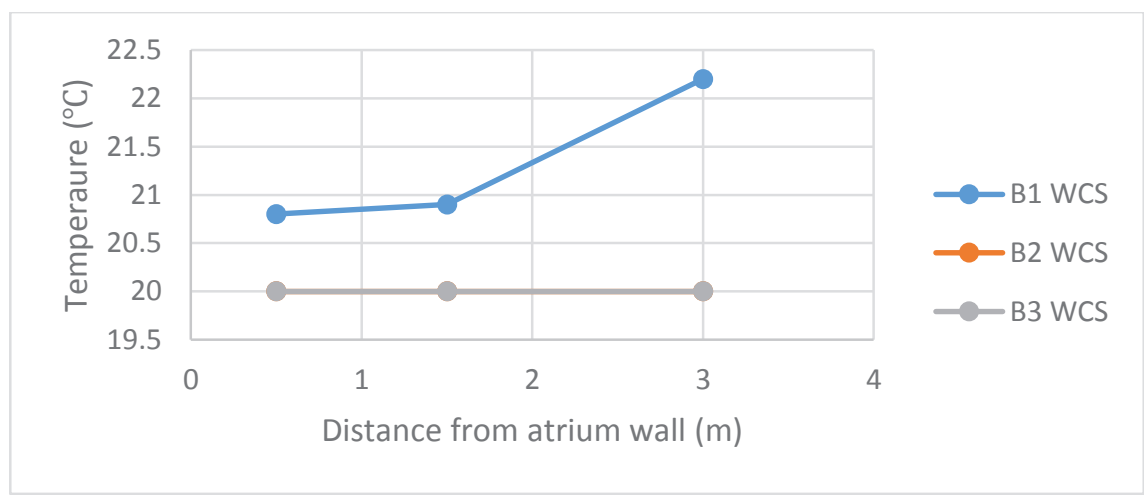

(b)

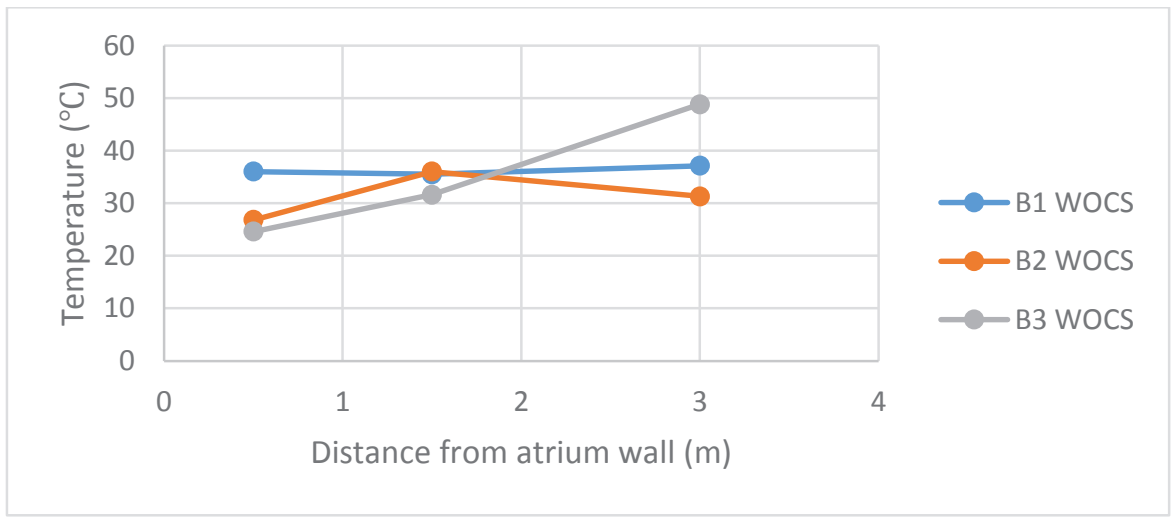

(c)

Fig. 2. Smoke temperature (a) along the balcony edges, (b) along the balcony breadth in case of using channel screen (WCS) and (c) along the balcony breadth in case of not using channel screen (WOCS). 
Case number 2 was selected to show the temperature difference along the balcony edges and inside each balcony. It can be seen in figure 2 (a) that the temperature along the balcony edges is higher for (WOCS) compared with (WCS). The temperature difference is illustrated in Table 2.

Table 2. Comparison of smoke temperature along balcony edges

\begin{tabular}{|c|c|c|c|c|}
\hline \multirow{2}{*}{$\begin{array}{c}\text { Sensor } \\
\text { symbol }\end{array}$} & $\begin{array}{c}\text { Sensor position } \\
\text { above balcony } \mathbf{1}\end{array}$ & \multicolumn{2}{|c|}{ Temperature } & Temperature \\
\cline { 3 - 4 } & $(\mathbf{m})$ & WCS & WOCS & \\
\hline difference (\%)
\end{tabular}

\subsection{Comparison of correlation}

The developed correlation to predict the height of smoke contamination is shown in figure 3 . The correlation has four parameters that are smoke plume depth below the spill edge (d) which is taken from FDS, smoke contamination height $(\mathrm{H})$ which is found from a visual observation of the smoke temperature contours, balcony breadth (b) and fire compartment opening width (w), the last two are structural dimensions of the atrium. Comparison of correlations illustrated that (WOCS) configuration has more smoke contamination indicated by a lower smoke height in the correlation.

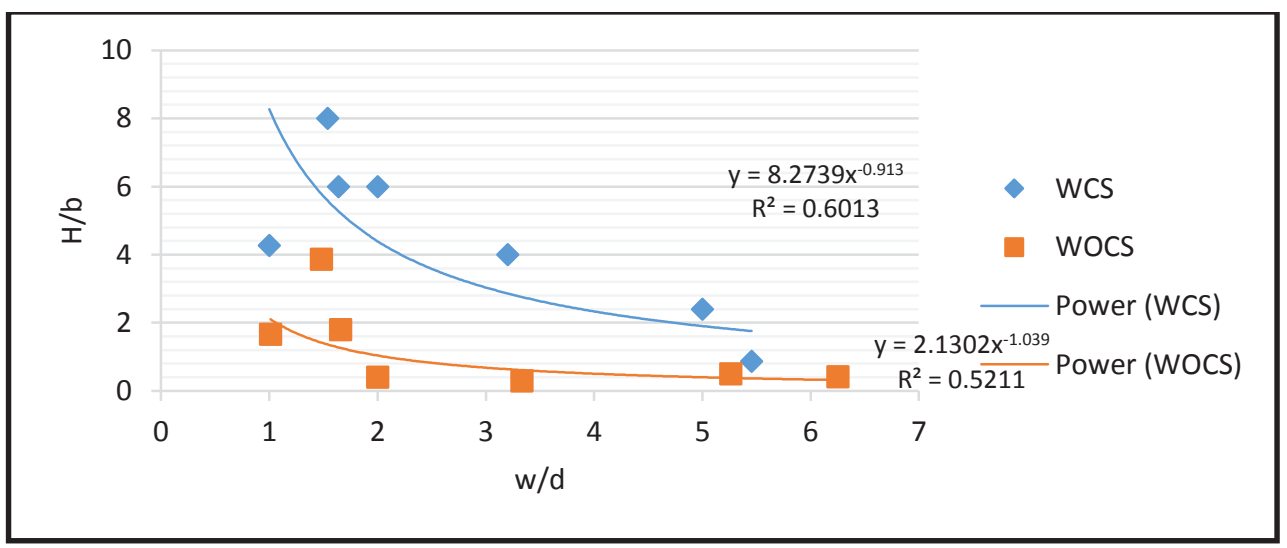

Fig. 3. Correlation to predict the smoke contamination height

\subsection{Comparison of smoke contamination height}

Table 3 shows the difference in occurrence of smoke contamination in case of using channel screen and not using it. It can be seen that the height of smoke contamination increased 
significantly for WOCS atrium compared with WCS atrium. Hence, the smoke contamination is more when no channel screens are used. On the other hand, the depth of the smoke plume is higher for WCS atrium because the smoke has been restricted from moving in a lateral direction and when the smoke hits the obstruction it losses buoyancy and becomes stagnant.

Table 3. Comparison of height and depth of smoke contamination

\begin{tabular}{|c|c|c|c|c|c|c|c|c|c|}
\hline Case & \multirow{2}{*}{$\mathbf{b}(\mathbf{m})$} & \multirow{2}{*}{$\mathbf{w}(\mathbf{m})$} & \multirow{2}{*}{ HRR(kW) } & \multicolumn{2}{|c|}{ WCS } & \multicolumn{2}{c|}{ WOCS } & \multicolumn{2}{c|}{ Comparison } \\
\cline { 5 - 10 } & & & & $\mathbf{H}$ & $\mathbf{d}$ & $\mathbf{H}$ & $\mathbf{d}$ & $\mathbf{\Delta H}(\mathbf{\%})$ & $\boldsymbol{\Delta d}(\%)$ \\
\hline 1 & 5 & 6 & 1581 & 12 & 1.2 & 2.5 & 1.14 & 79.2 & 5 \\
\hline 2 & 3 & 4 & 4740 & 12 & 1.25 & 0.89 & 1.2 & 92.6 & 4 \\
\hline 3 & 2 & 4 & 3160 & 12 & 2 & 0.8 & 2.12 & 93.3 & 0.0 \\
\hline 4 & 2 & 2 & 1581 & 12 & 1.22 & 3.6 & 1.206 & 70 & 1.1 \\
\hline 5 & 1.5 & 4 & 1581 & 12 & 2.6 & 5.8 & 2.3 & 51.7 & 11.5 \\
\hline 6 & 1.5 & 2 & 4740 & 6.4 & 2 & 2.5 & 1.98 & 60.9 & 1 \\
\hline 7 & 3 & 6 & 3160 & 2.6 & 1.1 & 1.25 & 0.96 & 51.9 & 12.7 \\
\hline
\end{tabular}

\section{Conclusion}

In this work, CFD simulation using FDS 6 software was conducted to investigate the effect of installing channel screens in the shopping mall's shops. 7 cases were selected in this study. The structural dimension of the atrium such as the balcony breadth and the fire compartment opening width were varying in each case. As well as the heat release rate. However, the depth of the down stand was kept constant and the balcony open up stand was used for all cases. It was found that, the omission of channel screens results in a greater lateral extent of smoke and hence, more smoke contamination in atrium upper balconies.

\section{References}

1. R. j.Hall, Burns, toxic gases, and other hazards associated with fires: Deaths and injuries in fire and non-fire situations. NFPA, Fire Analysis and Research Division, Quincy, MA, (2001).

2. Cox G. Compartment fire modelling. Combustion fundamentals of fire, 329-404 (1995)

3. R. Harrison "Entrainment of air into thermal spill plumes," Ph.D. thesis, University of Canterbury, (2009).

4. S. A. Hasnain, M. S. Nasif, W. Pao and R. Al-Waked Numerical investigation of smoke contamination in atrium upper balconies at different down stand depths, Building Simulation (2017)

5. S. A. Hasnain, M. S. Nasif, W. Pao and R. Al-Waked, Effect of Down Stand Depth Variation on Atriums Upper Balconies Smoke Contamination MATEC Web of Conferences, (2014)

6. Ho C. L., Li K. Y. and Spearpoint M. J. Numerical simulation of scale-model smoke contamination of upper atrium levels by a channelled balcony spill plume, Fire and Materials 37(8) 581-96 (2013)

7. K. McGrattan, S. Hostikka, J. Floyd, H. Baum, R. Rehm, W. Mell and R. McDermott Fire dynamics simulator (version 5), user's guide 1019(5) 1-186. (2010)

8. H. P.Morgan, B. K. Ghosh, G. Garrad, R. Pamlitschka, J. C. De Smedt and L. R. Schoonbaert Design Methodologies for Smoke and Heat Exhaust Ventilation. Construction Research Communication Ltd, Londres, R, U. (1999)

9. F.Tan , R. Harrison and M. J. Spearpoint Physical scale modeling of smoke contamination in upper balconies by a channeled balcony spill plume in an atrium Fire Sciences 1;28(4) 313-36.( 2010) 